\title{
WHAT DRIVES STUDENTS' INTENTION TO PLAGIARISE IN MONTENEGRO: THE MODERATING ROLE OF TEXT MATCHING SOFTWARE
}

\author{
Sanja Pekovic, Jovana Vukcevic, Dijana Vuckovic, Rajka Djkovic, Marijana Blecic
}

\begin{abstract}
We enrich the extended theory of planned behaviour (ETPB), to which we introduced two additional components - academic and computer literacy - to examine how different behavioural, moral and educational traits influence students' intentions to plagiarise. We argue that the relationship between components of the ETPB and students' intention to plagiarise is likely to be nuanced - and may display significant divergence depending on the students' awareness of text matching software utilisation. Using a sample of around 400 students from the University of Montenegro, our results partly confirmed that the extended theory of planned behaviour is an accurate predictor of the students' intention to plagiarise. More precisely, favourable attitudes towards plagiarism, low perceived behavioural control and low moral obligation influence positively students' intention to plagiarise. On the contrary, low subjective norms as well as both low academic and high computer literacy are found to be not significantly related to the students' intention to plagiarise. Further analysis reveals that the introduction of the moderator variable (students' awareness of text matching software utilisation) weakens the relation between the ETPB's components and students' intention to plagiarise. Overall, the obtained findings undoubtedly demonstrate that students' awareness of the utilisation of the text matching software acts as a strong impediment to the intention to plagiarise, mainly neutralizing the positive relations between the ETPB's components and intention to plagiarise.
\end{abstract}

Key words: Students' Intention to Plagiarise; the Extended Theory of Planned Behaviour; Academic Literacy; Computer Literacy; Text Matching Software; Moderating Approach

\section{Introduction}

Over the last several decades, the field of academic integrity entered the mainstream scholarship and academics around Europe started questioning different forms of academic misconduct and strategies for enhancing integrity and preventing non-ethical behaviour in academia (Melgoza \& Smith, 2008). The academic integrity, in broadest sense, could be defined as 'the values, behaviour and conduct of academics in all aspects of their practice (teaching, research and service)' (Macfarlane et al., 2014, p. 341). Violations of academic integrity remain one of the major global challenges in higher education (e.g. the International Centre for Academic Integrity reported that $70 \%$ of students cheat on tests), as academic dishonesty influences negatively the credibility of universities at the national and international level (Park, 2003). Moreover, the continued technological advancement enhances possibilities for non-ethical academic behaviour and creates additional forms of academic misconduct. Furthermore, it has been reported that the academic non-integrity proliferates into the business world, as some market actors blamed universities for corporate scandals since they failed 
to embed stronger ethical values into students' mind-set in preparing them for the workplace (Verschoor, 2003). Indeed, several studies reported a strong correlation between levels of academic dishonesty of undergraduate students and dishonesty in the working world of those same students later in their career (Carpenter et al., 2004; McCabe et al., 1996; Nonis \& Swift, 2001) - apparently, students who cheat in the academic setting are more likely to engage in unethical behaviour in the workplace later in their professional career.

Referring to the research of numerous scholars (Angell, 2006; Roig \& Caso, 2005; Whitley, 1998), Belter \& du Pré (2009) remind that the studies in the field consistently concluded that at least half of the college students reported they committed some sort of academic cheating during their studies. The scope and importance of this phenomenon sparked the interest of international scientific community, which profoundly analysed different aspects of academic (non)integrity, reasons for non-academic behaviour, frequency of cheating, impact of sanctions (Davis \& Ludvigson, 1995), compared strategies that have a better effect on students, e.g. fear-based vs. participation in discussion of cases (Compton \& Pfau, 2008), established relations between the moral perspective of students and the circumstances that lead to cheating (Eisenberg, 2004) and questioned number of related practices, strategies and challenges. Some researches differentiate between the planned and the so-called spontaneous cheating (Genereux \& McLeod, 1995) and some studies, such as Semerci (2006), reveals that students claim cheating to be unlawful and a forgery, but nonetheless cheat themselves. In this article, we will address the specific form of students' cheating, the well-known and wide-spread phenomena named plagiarism.

Plagiarism is considered to be one of the most common forms of academic dishonesty (Lathrop \& Foss, 2000; Park, 2003; Wilcox, 2005; Hodges et al., 2017). It can be broadly defined as the "unauthorized appropriation of another's work, ideas, methods, results or words without acknowledging the source or the original author" (Bilic-Zulle 2007; p. 146). Working on the sample of around 5000 students, McCabe et al. (2001) found that more than $65 \%$ students plagiarise on their written essays, while some scholars (e.g. Curtis \& Vardanega, 2016) argue the plagiarism rate to be even higher up to $80 \%$ in some student populations. Moreover, scholars argue that plagiarism is on the constant rise due to the possibilities provided by digital technologies and especially the Internet (Howard \& Davies, 2009; Towneley \& Parsell, 2004; Bradley, 2015; Rogerson \& McCarthy, 2017). This is in line with Wang's (2008) findings which reveal that approximately $30 \%$ of students used ideas, $15 \%$ of students used text and $5 \%$ of students used projects from the Web without indicating the appropriate source. As explained by Wilcox (2005), since the Internet provides the easy access to the information, it also gives the impression that one may appropriate others' ideas without attribution - as it can be accessed so easily. Thus, the author stresses that easy access to information is at the heart of many incidents related to plagiarism. Additionally, Ellery (2008) found support for the positive correlation between the frequency of the Internet use and the incidence of students' plagiarism.

Taking into consideration the scope and the severity of the problem, special attention has been dedicated to establishing profiles of those who plagiarise (Hodges et al., 2017) and understanding why they do it (Tindall \& Curtis, 2019). Yeung et al. (2018) found that 
poor information literacy and insufficient language skills represent some of the major factors instigating students to plagiarise. Jones (2011) identified that main reasons for plagiarising are students being too busy and the need to earn good grades. Batane (2010) highlighted that $75 \%$ of the participating students (in his survey) reported that they plagiarise mainly because of the laziness. Investigating the two-year students' selfreported perceptions of acts of plagiarism, Ferguson (2010) found that the demographic traits such as age and gender played important role in determining students who chose to engage in self-reported acts of plagiarism. Using a series of group interviews, Devlin \& Gray (2007) argue that contributing reasons for plagiarism are: institutional admission criteria, students' understanding of plagiarism, poor academic skills, a range of teaching and learning factors, personality factors and external pressures. McCabe (2005) concluded that the reasons driving students to plagiarise are related to the increase of competitiveness, pressures to achieve academically, awareness that their peers also plagiarise without being caught and possibility to obtain someone else's work easily. Underwood \& Szabo (2004) acknowledged the fear of failure as the main factor that increases students' probability to plagiarise. The authors further explained that the fear could be associated to many different repercussions such as parents' disappointment, scholarship loss and student not wanting to fail the course, which is why it often influences students' decision to cheat. Weinstein \& Dobkin (2002) corroborated that students' attitude towards plagiarism increases when the likelihood of being caught is low and the punishment minimal. Moreover, Davis et al. (1993), working on the sample of 6000 students, found that $36 \%$ of students indicated they would plagiarise in order to pass a certification test.

One of the most common mechanisms for combating plagiarism in academia is the use of the text matching software Turnitin (Bradley, 2015). It was developed by PhD students from the University of California, Berkeley in 1998. Today more than 30 million students use the software in one of the 15 ooo institutions spread over 140 countries. Researchers (e.g. Groark et al., 2001; Batane, 2010) agree that the software became extremely important device for universities in order to prevent plagiarism, as the plagiarism detection discourages potential plagiarisers. In the same vein, several scholars suggest that when student are aware that their writing assessments will be checked for potential plagiarism, they are less likely to plagiarise (Martin, 2005; Braumoeller \& Gaines, 2001). In other words, students' awareness of the existence of plagiarism detection software serves as an essential deterrent to plagiarism (Burke, 2004). On the other hand, as underlined by Willen (2004) even when students are aware that there is a practice regarding plagiarism prevention, they still may plagiarise when under pressure to perform well. Grebing (2015) stressed that there is a gap in literature regarding the effects of online tools on changing student behaviours and perceptions associated to academic dishonesty. Accordingly, it is crucial to understand if the students' behaviour towards plagiarism is dependent on their awareness of the existence and use of the text matching software. In addition, Batane (2010) also highlighted that other aspects of academic environment should be considered when examining the effectiveness of text matching software, thus we propose to examine the interaction effect between the ETPB and awareness of text matching software utilisation. 
Although plagiarism has been recognised as a global problem, affecting both the developed and developing world, Carnero et al. (2017) argue that in developing countries the problem is poorly discussed, which hinders the adoption of the preventive strategies. What more, den Ouden \& van Wijk (2011) underlined that the notions such as authorship, copyright and intellectual property have come into existence only recently in Western culture, while in Eastern cultures these notions are even less common. Actually, as explained by Brennan (2015), students' examination in Eastern countries barely ever relies on the essay-writing, which limits students' understanding of authorship, academic writing and plagiarism. Indeed, countries of Southeast Europe only recently started acknowledging the importance of academic integrity.

Montenegro, as one of the EU membership candidate countries, dedicated the last decade to aligning its higher education with the requirements, standards and practices of the EU universities. The topic of academic integrity, thus, revealed to be one of the major challenges for both academia and the society in the process of reforming higher education. Over the last several years, important steps have been taken in order to reduce the prevalence of academic dishonesty and plagiarism. In 2019, Montenegro was the first country in the region to adopt the Law on Academic Integrity, aiming to precisely define forms of academic misconduct and respective penalties for violating principles of academic integrity. Furthermore, all universities in the country ( 4 in total - 1 public and 3 privates) acquired the text matching software (iThenticate) through the national Ministry of Education, in the framework of the project supporting the development of higher education and research potential entitled 'Enhancement of HE Research Potential Contributing to Further Growth of the WB Region'. Accordingly, University of Montenegro adopted the decision to use the iThenticate software in April 2018. During the last year, the University engaged in number of activities aimed to support the implementation of the Law on Academic Integrity, improve overall academic culture, deliver policy recommendation, provide education and training to students and researchers in the area of anti-plagiarism and increase institutional capacities to combat plagiarism, corruption and fraud. It organised several seminars, workshops and roundtables aiming to enhance the understanding of existing and adoption of new mechanisms for combating plagiarism and other non-academic behaviour at institutional and national level. Furthermore, the University went through the certification in the field of academic integrity, acquiring the certificate from the Institute for Research and Action on Fraud and Plagiarism in Academia, University of Geneva in 2019.

Despite the increasing efforts to introduce new mechanisms for enhancing academic integrity, in Montenegro there was yet no comprehensive analysis of the impact of adopted measures. As indicated by Cortes-Vera et al. (2018) there has been a general lack of studies on the specific causes of plagiarism. In order to build an environment that will integrate academic behaviour as an integral part of teaching, learning and research that is suitable for Montenegrin context, it is necessary to provide researchbased evidence that would ground further recommendations on academic integrity and anti-plagiarism. This paper aims to address this gap in the field, by analysing how different factors influence students' intentions to plagiarise. In order to do so, the paper relies on data collected through the survey of students of University of Montenegro, 
which is the largest university in the country (enrolling around $80 \%$ of student population). The novelty of the approach consists in both employing the extended theory of planned behaviour (Ajzen, 1991) and using the two additional factors mostly absent from the research on academic integrity - namely the academic literacy and the computer literacy. Actually, the theory of planned behaviour (TPB) is used to predict behavioural intentions by analysing three factors: attitude toward the behaviour, subjective norms and perceived behavioural control. Scholars from the field extensively used the TPB as an efficient tool for analysing, understanding and predicting factors underlying the academic misconduct behaviours and intentions (Stone et al., 2007; Stone et al., 2009; Stowe, 2017; Passow et al., 2006; Salehi \& Ghasemzadeh, 2018). The extended model that we use in the paper includes an additional component moral obligation, which has been increasingly used in the analysis of the intentions to plagiarise and cheat (Chudzicka-Czupała et al., 2016; Harding et al., 2007), as well as the two components rarely used in these studies so far - academic and computer literacy. One exception is study of Camara et al. (2017), which uses the ethical theoretical framework called the theory of reasoned action (TRA) and the TPB to demonstrate that having knowledge of plagiarism decreases probability for academic misconduct to happen intentionally. Furthermore, regarding the computer literacy, this component may be found in work of Uzuna \& Kilis (2020) who considered Information and Communication Technologies (ICT) literacy, measured by the Internet, computer and information literacy, as indicators of the perceived behavioural control.

In Montenegro, but also in the larger region of Southeast Europe, there has been no study on the topic using this approach and the use of the TPB represents highly innovative concept. In addition, we add a moderator variable to our model - the text matching software, as according to Carroll (2009), although the software cannot eliminate the problem of plagiarism completely, it is important to analyse the moderator effects of the software when examining the predictors of students' intentions to plagiarise. The importance of moderator analysis is accented by Cohen et al. (2003) who argue that moderating approach is 'at the very heart of theory testing in the social sciences' (Cohen et al., 2009; p. 255). Different authors used moderating variables in their research of academic dishonesty and plagiarism. For instance, examining the factors associated with students' plagiarism, Bennett (2010) uses two moderating variables attitudes towards plagiarism and the intensity with which anti-plagiarism rules are enforced. Hoo Quah et al. (2012) analysed the relationship between ethical orientation of students and their attitudes toward plagiarism, using the religious orientation as a moderating variable. Van Zyl \& Thomas (2015) addressed perceptions of academic honesty of millennial university students considering the role of the gender, age, first language, faculty and qualification type as moderating variables.

As we indicated before, many scholars used the extended TPB (Stone et al., 2009; Chudzicka-Czupała et al., 2016; Stowe, 2017; Camara et al., 2017) and only few included academic and computer literacy (e.g. Camara et al., 2017; Uzuna \& Kilis, 2020) as a framework for studying students' cheating and plagiarism intentions. However, we have not so far encountered studies merging the extended theory of planned behaviour (ETPB) and moderating factors. The importance of analysing not only the direct effects of the TPB's components has been demonstrated in recent work of Hendy \& 
Montargo (2019) who using the TPB model analysed the mediating role of justification of cheating. Accordingly, the aims of the present study are threefold: (1) to identify the ETPB's components as well as socio-demographic characteristics that drive students' intention to plagiarise (2) to analyse the moderating role of text matching software; (3) to define mechanisms that would advance academic integrity and ethical behaviour in Montenegro. In general, empirical findings will help us to better define strategy related to the quality of research and higher education in Montenegro by spreading the culture of academic integrity, promoting ethical behaviour and preventing plagiarism and other types on non-ethical practices in academic work. Figure 1 depicts our research framework.

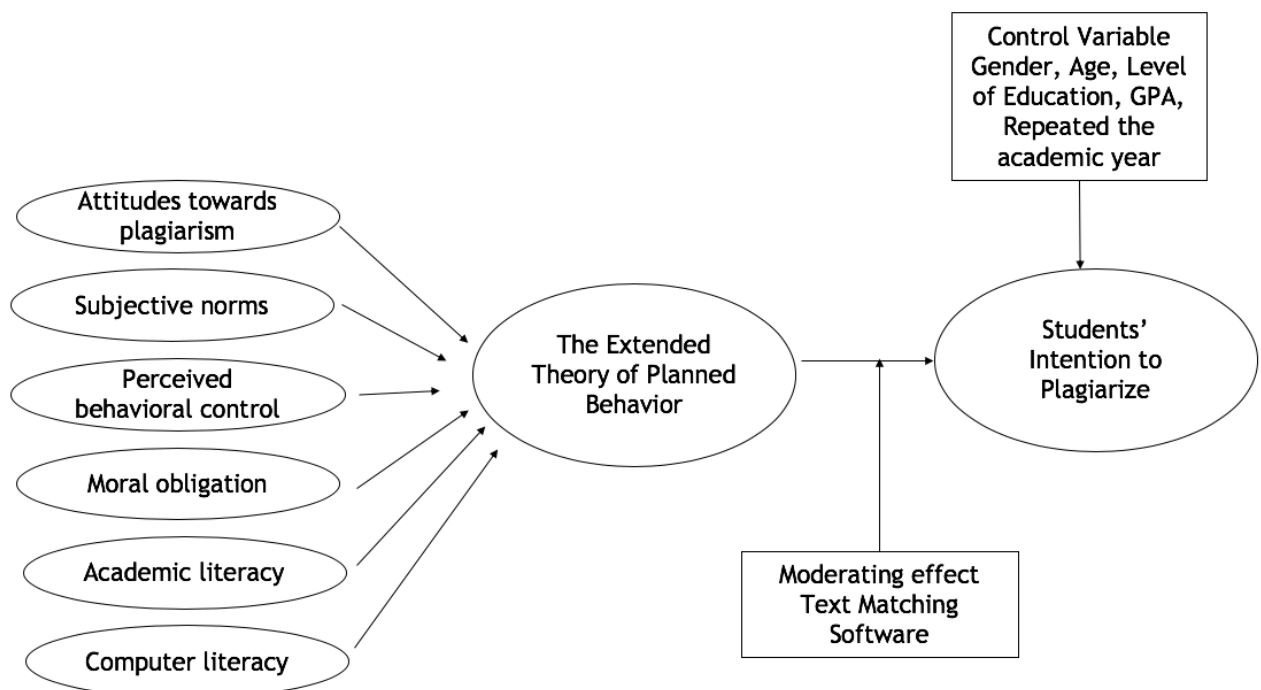

Figure 1. Theoretical model

The rest of the paper is organized in the following structure. In the next section, we discuss the existing relevant literature and develop our hypotheses. In the following section, we analyse our data and empirical strategy. Then, we report and discuss our main results. Finally, we conclude by summarizing the main findings and providing the implications and limitations of our study.

\section{Literature review and Hypotheses development}

Number of studies from the field (e.g. Chudzicka-Czupała et al., 2016; Alleyne \& Phillips, 2011; Harding et al., 2007; Stone et al., 2009; Whitley, 1998) use the Ajzen's (1991) model the theory of planned behaviour as the most appropriate theoretical framework for explaining academic dishonesty. This theory represents a conceptual extension of the Fishbein \& Ajzen's (1975) theory of reasoned action (TRA) which proposes that human behaviour results from the attitude towards that particular 
behaviour and from the subjective norms. In 1991, Ajzen adds an additional variable for predicting people's behaviour - the perceived behavioural control. The author defined intention as people's willingness to try or their planning effort to perform the behaviour while attitude toward a certain behaviour presents personally held beliefs concerning that behaviour. Subjective norm is considered as the social component which indicates person's perception of how others view the behaviour in question and whether or not they would approve the action. Finally, perceived behavioural control explains discrepancies between intentions and behaviours.

This influential theory has been further expanded by Beck \& Ajzen (1991), who introduced additional dimension to the model related to the moral obligation. As explained by Chudzicka-Czupała et al. (2016), moral obligation explains personal feelings associated with the obligation to engage in a specific behaviour (e.g. sense of duty), or to the refusal to undertake it (e.g. guilt, reluctance, or the sense that the behaviour is incompatible with the individual's values and principles). Using the theory of planned behaviour as a model of academic dishonesty, Harding et al. (2007) provide several arguments that support the inclusion of moral obligation dimension into this framework. The authors argue that as the decision to cheat is an ethical one, a moral dimension may be critical in such decisions; considering that college has important influence on gains in moral reasoning scores, there may be significant differences in this component according to the college level; but also, there may be differences in the effect of a moral component by discipline.

Although the ETPB provides important framework to analyse students' intention toward academic misconduct, over the years' scholars have been consistently upgrading the model adding components they considered significant for explaining the phenomenon. Harding et al. (2007) stress that scholars should continue to examine other constructs that can further explain intention to cheat and extend the original theory of planned behaviour model by introducing additional component. Imran \& Nordin (2013) added ethical belief (ETB) to the TPB components. In this paper, besides the moral obligation, we add two additional components that are considered important for explaining students' intention to plagiarise - namely, the academic literacy and the computer literacy. According to Reid (2005), academic literacy encompasses not only the operational literacy (clear writing, correct spelling and punctuation), but also the cultural literacy (capacity to structure an essay, including introduction and conclusion, quote and paraphrase other's ideas, write references) and the critical literacy (analysing an assignment question, reading academic texts and reflecting critically on ideas and experiences). Computer literacy has been defined by Uzun \& Kilis (2020) as capability or skill to use the computer effectively. The rationale for choosing academic literacy is based on the fact that plagiarism can arise from the lack of knowledge of proper quotation and citation rules or of interrelationships of meaning, knowledge, expression and argument (Park, 2003). For example, the inadequate writing skills can lead to direct copying of text without acknowledging the source (Pecorari, 2008). Therefore, in order to avoid plagiarism, students need to understand the rules and standards of academic writing (Selemani et al., 2015). What more, several scholars (Leask, 2006; Macdonald \& Carroll, 2006; Pecorari, 2008; Walker, 2010) underline that good academic writing skills are indispensable in order to reduce incidence of plagiarism. Furthermore, Uzun \& Kilis 
(2020) argue that students with high computer literacy have better skills to manipulate the contents and provide correct source.

Park (2003) indicated that plagiarism can be considered as a form of cheating or academic misconduct or dishonesty. Therefore, in order to develop our hypotheses, we will use literature that tackles both cheating and plagiarism.

\section{Attitudes toward plagiarism}

Attitude toward behaviour has been defined by Beck \& Ajzen (1991) as the extent to which an individual approves or disapproves that specific behaviour. As early as in 1975, Fishbein \& Ajzen (1975) underlined that an individual who positively evaluates a specific behaviour is more likely to exhibit behavioural intentions toward the action and ultimately to perform that particular behaviour. Several scholars empirically confirmed that positive attitude toward plagiarism will drive students' intention to plagiarise. For instance, drawing on both the TPB and the General Theory of Crime (GTC), Curtis et al. (2018) concluded that students' attitude significantly predicts their engagement in plagiarism. In fact, their study demonstrated that students which expressed more negative attitudes toward plagiarism showed less intention to plagiarise and engaged in plagiarism less often. In the same vein, working on the sample of students from 7 countries (Poland, Ukraine, Romania, Turkey, Switzerland, United States, and New Zealand), Chudzicka-Czupała et al.'s findings (2016) demonstrate that attitudes predict students' intentions to engage in academic cheating. Similarly, using a sample of 363 undergraduate students at the West Indian University, Alleyne \& Phillips (2011) found that attitudes were significant predictors of students' intentions to perform academic dishonesty behaviours in the form of cheating and lying. Harding et al. (2007), working on a sample of 527 randomly selected students show that attitude towards cheating influence positively their intention to engage in such behaviour. According to Simon et al. (2004), students with favourable attitudes toward academic integrity policies are also more likely to report cheating.

This is noteworthy, the literature also problematized this measure - as there is evidence that even though students may have negative attitude toward academic dishonesty, they may still engage in academically dishonest behaviours (Davis et al., 1992; Smyth \& Davis, 2004; Semerci, 2006; Park \& Blenkinsopp, 2009). For instance, Semerci (2006) revealed that even though students consider that cheating is illegal and a forgery, they still do cheat, while Smyth \& Davis (2004) found similar inconsistency while $92 \%$ of the respondents in their sample reported that cheating is unethical, $45 \%$ admitted that according to them cheating is acceptable social behaviour.

In line with the previous arguments, we propose the following hypothesis:

Hypothesis 1: Favourable attitudes toward plagiarism increase students' intention to plagiarise.

\section{Subjective norms}

It has been widely acknowledged that people's behaviour is influenced by the behaviour of others - or by their expectations of how the others will behave. Drawing on the 
literature on social norms, scholars from the field concluded that the perception of peer behaviour presents an influential predictor of one's decision-making regardless of the perceptual accuracy (Perkins, 2003; Engler et al., 2008; Camara et al., 2017). Accordingly, Engler et al. (2008) argued that the presence of cheating culture at the campus increases students' propensity to cheat. Existing empirical research showcased that the subjective norms have a direct impact on the intention to plagiarise. For instance, in the previously mentioned analysis of Alleyne \& Phillips (2011), the findings confirmed the positive relationship between subjective norms and intention to plagiarise. Camara et al. (2017) also found the positive correlation indicating that students with less intention to plagiarise do not believe that plagiarism is acceptable to their family, friends or peers. These results were also confirmed by Imran \& Nordin (2013), Hsiao (2015), Chudzicka-Czupała et al. (2016), Curtis et al. (2018). In an influential study from 1993, McCabe \& Trevin revealed the importance of the perception of peer behaviour - when students reported that they have seen their peers cheating, they were more prone to perceive cheating as an acceptable behaviour. According to the authors, the peers' academic misbehaviour is likely to become a justification - " $a$ normative support for cheating". Even more, McCabe et al.s (2002) further studies of honour codes and other contextual influences on academic integrity, emphasized that the perception of peers' behaviour acts as the best predictor of cheating behaviour.

Considering the previous reasoning, we define the following hypothesis:

Hypothesis 2: Low subjective norms increase students' intention to plagiarise.

\section{Perceived Behavioural Control}

Perceived behavioural control, according to Asare (2015) could be understood as the "people's perception of the ease or difficulty of performing the behaviour of interest". It measures perceived obstacles to conducting certain behaviour (such as cheating and plagiarism). Previous literature analysing the effect of perceived behavioural control on cheating intentions provided conflicting conclusions. On the one hand, it is argued that when an individual faces the important obstacle to certain behaviour, the low perceived control of behaviour may discourage him/her from undertaking that particular behaviour (Chudzicka-Czupała et al., 2016). Accordingly, several scholars empirically confirmed this positive relationship (Camara et al., 2017; ChudzickaCzupała et al., 2016; Alleyne \& Phillips, 2011). McCabe et al. (2002) revealed that probability of being caught while cheating acts as a strong predictor of the extent of dishonesty in which student is ready to engage. Most recently, Handy \& Montargot (2019) analysing the academic dishonesty amongst business school students in France using the TPB found that the perceived behavioural control was positively related to the self-reported cheating behaviour. On the other hand, according to Harding et al. (2007), the perceived behavioural control does not predict cheating behaviour, as participants' perceived ease of cheating has little bearing on their actual cheating. Similar conclusion was obtained by Passow et al. (2006) who argue that perceived behavioural control does not explain importantly the cheating behaviour.

Considering that the previous discussion proposes arguments that support both positive and neutral effects, we define the following competing hypotheses: 
Hypothesis 3a: Low perceived behavioural control increases students' intention to plagiarise.

Hypothesis 3b: Low perceived behavioural control does not influence students' intention to plagiarise.

\section{Moral Obligation}

The original TPB model was expanded by Beck \& Ajzen (1991) to accommodate fourth component - moral obligation. As previously explained, the moral obligation refers to the individuals' sentiment of obligation to behave in certain manner or the refusal to conduct such behaviour (Chudzicka-Czupała et al., 2016). It reflects the degree to which individual considers particular behaviour to be compatible with his/her values, principles and ethical standards. The literature argues that as the academic dishonesty encompasses also the moral aspects, moral obligation should be considered as an important predictor of the cheating intention (Cronan et al., 2018; Uzun \& Kilis, 2020). Actually, the fact that people are ready to cheat or steal other people's idea demonstrates that there have been minimal advances in moral behaviour (Semerci, 2006). Beck \& Ajzen (1991), who proposed that moral obligation should be introduced in the TPB, were among the first to claim that moral obligation was an important driver of students' intentions to cheat. In words of Imran \& Norodin (2013), high levels of ethical consciousness and moral development decrease likelihood that students will behave in academically dishonest ways. Inversely, students with low moral standards are more likely to engage in non-ethical behaviour. Several previous scholars empirically confirmed these findings such as Passow et al. (2006), Harding et al. (2007), Alleyne \& Phillips (2011), Chudzicka-Czupała et al. (2016).

We therefore expect the following:

Hypothesis 4: Low moral obligation increases students' intention to plagiarise

\section{Academic literacy}

Academic literacy refers to the capacity to write, read and communicate in academic setting, following the rules and standards of the academic discourse (Calvo et al., 2020). It is one of the essential skills which students and academic staff need to master in order to engage in debates on academic subjects using the scientific methods. The rigorous practice of academic writing is thus indispensable in order to strengthen students' academic capacity and academic integrity. Indeed, Bellack (2004) considers high standards in written communication to be the main feature of academic integrity. Selimani et al. (2018) further develop this idea highlighting that in order to decrease the incidence of plagiarism it is indispensable to enhance the academic writing capacities. Camara et al. (2017) argue that having knowledge of what is considered to be plagiarism reduces the probability that students will actually commit plagiarism. Providing the students practice in proper paraphrasing, Barry (2006) concluded that students' knowledge about plagiarism was higher after the academic writing exercise than before. Furthermore, the author argues that plagiarism occurs when students are not familiar with the correct protocols for referencing the academic work. The findings by Belter 
\& du Pré (2009) follow the same line of argumentation indicating that the important extent of plagiarism encountered was the result of inadequate knowledge about proper quotation and citation rules. However, academic writing literacy is considered to be a complicated activity as it includes summarizing, quoting and paraphrasing other authors' concepts and ideas (Bailey, 2011). Thus, poor academic writing skills are likely to increase the probability of students' plagiarism (Selimani et al., 2018). Husain et al. (2017) suggest that students who lack the academic writing literacy are more tempted to plagiarise. Similarly, Yeung et al. (2018) conclude that poor academic literacy entails poor academic behaviour. Several scholars confirm that students plagiarised unintentionally due to a lack of knowledge about academic writing and plagiarism (Scouller et al., 2008; Ramzan et al., 2012). Consequently, in her book, Pecorari (2008) stresses that institutional plagiarism policy should be more focused on development of academic writing skills.

Taking into consideration that a number of authors claimed a positive correlation between being academically illiterate and committing plagiarism, we formulate the following hypothesis:

Hypothesis 5: Low academic literacy skills increase students' intention to plagiarise.

\section{Computer Literacy}

Lathrop \& Foss (2000) argue that the availability of online resources represents a major factor that contributes to the increase of plagiarism among students. Uzuna \& Kilis (2020), working on a cross-sectional survey data which includes 588 university students, demonstrated that information literacy is a significant predictor of students' intention to engage in plagiarism, but both the Internet literacy and the computer literacy do not drive students' intention to plagiarise. Similar results were obtained by Trushell et al. (2012) who found that ICT capability and the Internet did not correlate significantly with cheating behaviours. In the same vein, Selwyn (2008) demonstrated that the likelihood of plagiarising online was only weakly associated with the students' ICT expertise. On the other side, Eret \& Ok (2014) find that students with more experience in using computers reported greater tendencies to plagiarise. They argue that obtained findings could be due to the fact that as students feel more selfconfident in using computer and the Internet, they have more skills and knowledge about manipulating an electronic resource. Their findings are supported by those from Newstead et al. (1996) and Selwyn (2008) who reveal that students taking the computer science as a major plagiarise more frequently than students with other majors. The line of findings is further supported by Ashworth et al. (1997) and Campbell et al. (2000) who conclude that the increase in plagiarism is related to students' greater knowledge of and familiarity with the information systems, the Internet, online electronic information sources, and the ease with which the information can be retrieved and used.

Using the previous scholarly discussion as a starting point, we defined competing hypotheses as follows:

Hypothesis 6a: High computer literacy skills increase students' intention to plagiarise. 
Hypothesis 6b: High computer literacy skills do not influence students' intention to plagiarise.

\section{Moderating role of Text Matching Software}

The text matching software such as iThenticate is considered to be one of the most effective tools for reducing students' intention to plagiarise (Ercegovac \& Richardson, 2004; Bradley, 2015; Curtis \& Vardanega, 2016). Previous scholars (Bennett, 2005; Sutherland-Smith \& Carr, 2005; Murray, 2006; Davis, 2007) examined the learning role of these software, indicating that they can deter students from plagiarising. Another stream of research looked at how students' awareness that their work will be checked by plagiarism detection software can increase their efforts to avoid plagiarism. Actually, as students realize they can be easily caught in plagiarism due to the use of software, they tend to be afraid of the punishment which discourages them from plagiarising. This is confirmed by previous analyses arguing that fear of being caught prevent academic dishonesty (Diekhoff et al. 1999; McCabe \& Treviño, 1997; McCabe et ac., 2001, 2002; Ledwith \& Rísquez, 2008). Accordingly, Burke (2004) suggests that if students are aware that their papers are checked by the text matching software, it could decrease the incidence of plagiarism. In this sense, Batane (2010) revealed that after Turnitin was introduced to the students of the University of Botswana, their plagiarism level dropped by $4.3 \%$. As the author explains the plagiarism did not completely disappear but the software had a significant impact on reducing the rate of plagiarism. In the same vein, Bilic-Zulle et al. (2008) compare two groups of students, noting that the students from $2002 / 2003$ who were only warned against plagiarism had $21 \%$ of plagiarised text on average in their essays, whereas the students from 2004/2005 who were warned that their essays would be checked through the plagiarism detection software (and that those who plagiarised would be penalized) had only $2 \%$ of plagiarised text. Similar results were obtained by Martin (2005) who reported that students who hold a stronger belief that plagiarism will be detected may be less likely to plagiarise. What more, the author concludes that students' awareness of the detection software will engage them in the learning process, which will further decrease plagiarism in the long run.

Previous research established that certain correlations will change direction, gain or lose statistical significance when a moderator variable is introduced (see Baron \& Kenny,1986 for more information). In this paper, we consider students' awareness of the text matching software utilisation as a potential moderator since it is theoretically possible that the ETPB's components might have a different impact on students' intention to plagiarise in presence of this additional criteria. In simple terms, this means that, for example, even if students having positive attitude toward plagiarism show more intentions to plagiarise, when they are aware of the existence and use of the text matching software, they might however avoid plagiarising (show less or no intention to plagiarise) as the positive correlation between attitudes and intentions might be buffered by the moderating variable. Thus, we formulated the following hypotheses:

Hypothesis 7a: The relationship between attitudes toward plagiarism and intention to plagiarise is moderated by students' awareness of the text matching software utilisation, 
such that the students' awareness of text matching software utilisation weakens the positive relation between favourable attitude towards plagiarism and intention to plagiarise.

Hypothesis $7 b$ : The relationship between subjective norms and intention to plagiarise is moderated by students' awareness of the text matching software utilisation, such that students' awareness of the text matching software utilisation weakens the positive relation between low subjective norms and intention to plagiarise.

Hypothesis 7c: The relationship between level of perceived behavioural control and intention to plagiarise is moderated by students' awareness of the text matching software utilisation, such that students' awareness of the text matching software utilisation weakens the positive relation between low perceived behavioural control and intention to plagiarise.

Hypothesis 7d: The relationship between moral obligation and intention to plagiarise is moderated by students' awareness of the text matching software utilisation, such that students' awareness of the text matching software utilisation weakens the positive relation between low moral obligation and intention to plagiarise.

Hypothesis 7e: The relationship between academic literacy skills and intention to plagiarism is moderated by students' awareness regarding text matching software utilisation, such that students' awareness of the text matching software utilisation weakens the positive relation between low academic literacy skills and intention to plagiarise.

Hypothesis $7 f$ : The relationship between computer literacy skills and intention to plagiarise is moderated by students' awareness of the text matching software utilisation, such that students' awareness of the text matching software utilisation weakens the positive relation between high computer literacy skills and intention to plagiarise.

\section{Methodology}

\section{Data}

In order to answer the research questions and examine proposed hypotheses, we created a questionnaire solely dedicated to the issue of academic integrity. The questionnaire is designed to reflect experiences from similar scholarly endeavours (e.g. McCabe, 2005; Bradinova, 2006; Boehm, 2008; Broeckelman-Post, 2009; Bradley, 2010; Alleyne \& Phillips, 2011; Curtis et al. 2013; Stout, 2013; Benett, 2017) which analysed the topic of academic integrity. More precisely, other than the general information on students' background, the questionnaire included additional sections associated to students' perception of their academic skills, academic work environment, promotion of academic integrity, institutional policies associated with the academic integrity, academic dishonesty, motivations for academic dishonesty, workplace integrity, etc.

We conducted a survey and collected data from students of University of Montenegro between December 2019 and February 2020. More precisely, the questionnaire was administered to a representative sample of the University of Montenegro student population including all 19 faculty units (Faculty of Architecture; Faculty of Biotechnology; Faculty of Civil Engineering; Faculty of Drama; Faculty of Economics; Faculty of Electrical Engineering; Faculty of Fine Arts; Faculty of Philosophy; Faculty of Philology Faculty of Law; Faculty of Maritime Studies; Faculty of Mechanical Engineering; Faculty 
of Medicine; Faculty of Metallurgy and Technology; Faculty of Natural Sciences and Mathematics; Faculty of Political Sciences; Faculty of Tourism and Hotel Management; Faculty for Sport and Physical Education; Music Academy). In addition, we strived to ensure a representative pool regarding gender, age, level of education. More than 500 university students participated in this survey. We eliminated those observations with the missing values relevant for this paper, which resulted in a final sample of 401 usable observations.

\section{Measure}

Students' intention to plagiarise. Our dependent variable entitled INTENTION TO PLAGIARISE was measured by five items adapted from Harding et al. (2007), Imran \& Nordin (2013), Chudzicka-Czupała et al. (2016), Camara et al. (2017) and Uzun \& Kils (2020). The items included are the following: (1) Sometimes I feel tempted to plagiarise because so many other students are doing so; (2) If my roommate gives me the permission to use his or her paper for one of my classes, I do not think there is anything wrong in doing so; (3) Plagiarism is justified if the professor assigns too much coursework; (4) The punishment for plagiarism should be light because we young people are just learning in vain; (5) I do not think plagiarism is right, but there are still some situations in which a student might be forced to plagiarise in order to get a decent grade in a course. For each item, respondents were requested to indicate to what extent they agreed with the statement regarding the academic issue. The items were presented on a 5-point Likert-type scale, ranging from 1 (strongly disagree) to 5 (strongly agree). The Cronbach alphas for the intention scale is 0.70 .

Attitudes toward plagiarism. Our first independent variable denoted ATTITUDES was measured by eleven items adapted from e.g., Stone et al. (2009), ChudzickaCzupała et al. (2016) and Camara et al. (2017). The following items are included: (1) Students should be held responsible for monitoring the academic integrity of other students (inversely coded) (2) If I had known that another student in the class was planning to plagiarise a paper, I would try to persuade him or her not to plagiarise (coded inversely); (3) If I discovered that a student had plagiarised, I would try to persuade him or her to confess (coded inversely); (4) Plagiarism is always wrong, regardless of the circumstances (coded inversely); (5) If a student in my class got caught plagiarising a paper, he or she would deserve to fail the course (coded inversely); (6) If a student buys or downloads free research paper and turns it in unchanged with his or her name as the author, the student should be expelled from the university (coded inversely); (7) If students caught plagiarising would receive a special grade for cheating on their permanent transcript, that policy would deter many from plagiarising (coded inversely); (8) Students should require to take a class in ethical behaviour as a part of the general education requirements (coded inversely); (9) Faculties in all disciplines should address integrity and ethical behaviour throughout their courses; (10) Person can learn to have personal integrity from learning about the academic integrity (coded inversely); (11) Plagiarism is as bad as stealing the final exam ahead of time and memorizing the answers (coded inversely). The Cronbach's Alpha for this construct equals 0.70 . 
Subjective norms. Our second independent variable called SUBJECTIVE NORMS includes fifteen items adapted from Stone et al. (2009). The items we use to measure SUBJECTIVE NORMS component are as follows: (1) Writing or providing a paper for another student; (2) Copying few sentences from written source without citing; (3) Turning in a paper copied from another student; (4) Turning in a paper obtained in large part from a term paper "mill" or website that did not charge this information; (5) Fabricating/falsifying a bibliography; (6) Turning in a paper written by someone else; (7) Writing a paper for someone else to submit; (8) Copying material 'word for word' from the written source; (9) Selling a self-written paper to another student to submit it as his/hers; (10) Buying a paper online to submit; (11) Copying a few sentences of the material from an Internet source without acknowledging it in the paper; (12) Submitting the same paper for two courses; (13) Copying directly from a source (word for word) without citing; (14) Listing sources in a bibliography after only reading the abstract of an article; (15) Listing sources in a bibliography that were not actually read. For each item, respondents were requested to indicate how often the previous situations occur at their faculty. Items were presented on a 5-point Likert-type scale, ranging from 1 (never) to 5 (very often). The Cronbach's Alpha value is 0.95 .

Perceived Behavioural Control. Variable named PERCEIVED BEHAVIOURAL CONTROL is comprised of seven items adapted from Stone et al. (2009), Alleyne \& Phillips (2011) and Hsia (2015). The included items refer to the motivations for plagiarising and are as follows: (1) Belief that they will not get caught; (2); Belief that those who are caught are not punished; (3) Belief that those who plagiarise will get a better grade; (4) Chances of getting caught are thin; (5) Belief that other students are doing the same; (6) Everyone cheats; (7) What some consider cheating, I do not consider cheating. Items were presented on a 5-point Likert-type scale, ranging from 1 (strongly disagree) to 5 (strongly agree). The Cronbach's Alpha equals to o.87.

Moral Obligation. Variable MORAL OBLIGATION is assessed following previous scholars such as Harding et al. (2007), Alleyne \& Phillips (2011) and Uzun \& Kils (2020). Actually, the variable is represented by following: (1) Plagiarism is against my ethical values. Item was presented on a 5-point Likert-type scale, ranging from 1 (strongly disagree) to 5 (strongly agree), but we coded it inversely.

Academic Literacy. In line with the previous research (e.g. Stout, 2013; Selimani et al., 2018), the ACADEMIC LITERACY variable includes the following items: (1) Able to compose and revise clear and coherent essays and basic documents; (2) Able to develop essays with clear thesis statements and topic sentences as well as the specific support; (3) Able to analyse reading; (4) Able to express critical thinking skills in discussions; (5) Able to apply argumentation in writing; (6) Able to express critical thinking skills in my writing; (6) Able to proofread my own papers; (7) Able to provide feedback to other writers regarding their papers; (8) Able to apply library and research skills to locate and organize research data; (9) Able to employ appropriate tone, diction (voice) in writing; (10) Able to employ appropriate grammar and punctuation correctly; (11) Able to write a paper based on a case study; (12) Able to employ the requested referencing style (APA, Harvard, etc); (13) Able to demonstrate how to use quotes and citations correctly; (14) Able to demonstrate how to paraphrase correctly; (15) Able to demonstrate what an abstract should look like. We used 5-point Likert scales, ranging from 1 (strongly 
disagree) to 5 (strongly agree), but we coded it inversely. The Cronbach's Alpha equals o.90.

Computer Literacy. Following Eret \& Oak (2014) and Uzun \& Kils (2020), we created variable denoted COMPUTER LITERACY corresponding to students' perception about his/her computer knowledge and related technical skills. We used 5-point Likert scales, ranging from 1 (strongly disagree) to 5 (strongly agree).

Text Matching Software. Drawing on previous work from Martin (2005), Bilic-Zulle et al. (2008), Batane (2010)and Brenan (2015), we use binary variable denoted TEXT MATCHING SOFTWARE, corresponding to whether students are aware that the text matching software is used at their faculty. ${ }^{1}$

Furthermore, we control for our students' socio-demographic characteristics that are found in previous literature (e.g. Passow et al., 2006; Harding et al., 2007; Alleyne \& Phillips, 2011; Chudzicka-Czupała et al., 2016) to be important drivers of students' intention to plagiarise. More precisely, we include the following control variables: (1) gender; (2) age; (3) level of education; (4) cumulative grade point average; and (5) if the student repeated the academic year.

In Table 1 we present the descriptive statistics of variables used.

\section{Empirical model}

The relationship between the independent variables and our dependent variable $I N$ TENTION TO PLAGIARISE is tested using an Ordinary Least Square (OLS) regression. The model can be written as:

$$
y_{i}=X_{i} a+e_{i}
$$

where $y_{i}, X_{i} a$ and $e_{i}$ represent INTENTION TO PLAGIARISE, the vector of exogenous variables, estimated coefficients, and error term, respectively.

Noteworthy, in order to test our moderating effect, we interact our main independent variable i.e., ATTITUDES, SUBJECTIVE NORMS, PERCEIVED BEHAVIOURAL CONTROL, MORAL OBLIGATION, ACADEMIC LITERACY andCOMPUTER LITERACY with variable representing TEXT MATCHING SOFTWARE to see if it moderates the relation between our independent and dependent variables. In order to avoid multicollinearity between the interaction terms and their components, we follow the approach suggest by Aiken \& West (1991). More precisely, we mean-centre the direct terms by subtracting the mean of each variable from the values of each observation.

\section{Results}

The OLS estimation results are provided in Table 2. The fit is reasonable, with a pseudo R-squared of 0.248 for direct effect model while it is 0.271 for moderating effect.

\footnotetext{
${ }^{1}$ Due to relatively large number of missing values regarding variable TEXT MATCHING SOFTWARE, we set the missing values to be equal to zero. Actually, we supposed that students who did not answer the relevant question were not aware about text matching software as they did not answer any of the questions associated with the software and simply continued to answer further questions. In order to check whether it significantly influences our results, we run the same model without setting missing variable equals to zero and received similar findings. Further results are available upon request.
} 
Table 1

Definition of variables and descriptive statistics $(N=401)$

\begin{tabular}{|l|r|r|r|c|}
\hline Variables & Mean & \multicolumn{1}{|c|}{ SD } & Min & Max \\
\hline INTENTION TO PLAGIARISE & 13.70 & 3.84 & 5 & 25 \\
\hline ATTITUDES & 26.91 & 6.67 & 11 & 56 \\
\hline SUBJECTIVE NORMS & 37.33 & 15.53 & 15 & 75 \\
\hline PERCEIVED BEHAVIOURAL CONTROL & 23.26 & 6.08 & 7 & 35 \\
\hline MORAL OBLIGATION & 2.36 & 1.08 & 1 & 5 \\
\hline ACADEMIC LITERACY & 30.66 & 10.10 & 15 & 64 \\
\hline COMPUTER LITERACY & 4.21 & 0.97 & 1 & 5 \\
\hline TEXT MATCHING SOFTWARE & 0.29 & 0.45 & 0 & 1 \\
\hline GENDER & 0.66 & 0.47 & 0 & 1 \\
\hline AGE & 21.99 & 0.45 & 19 & 48 \\
\hline 1ST YEAR UNDERGRADUATE & 0.21 & 0.41 & 0 & 1 \\
\hline 2ND YEAR UNDERGRADUATE & 0.20 & 0.40 & 0 & 1 \\
\hline 3RD YEAR UNDERGRADUATE & 0.32 & 0.47 & 0 & 1 \\
\hline 4TH YEAR UNDERGRADUATE & 0.19 & 0.39 & 0 & 1 \\
\hline MASTER LEVEL & 0.07 & 0.25 & 0 & 1 \\
\hline PhD LEVEL & 0.01 & 0.12 & & \\
\hline CULMULATIVE GRADE POINT AVARAGE-A & 0.14 & 0.35 & 0 & 1 \\
\hline CULMULATIVE GRADE POINT AVARAGE-B & 0.27 & 0.44 & 0 & 1 \\
\hline CULMULATIVE GRADE POINT AVARAGE-C & 0.31 & 0.46 & 0 & 1 \\
\hline CULMULATIVE GRADE POINT AVARAGE-D & 0.22 & 0.41 & 0 & 1 \\
\hline CULMULATIVE GRADE POINT AVARAGE-E & 0.05 & 0.22 & 0 & 1 \\
\hline REPEATED A YEAR & 0.27 & 0.44 & 0 & 1 \\
\hline
\end{tabular}

Comparison between R-squared of direct and moderating effect models indicates that introducing moderating effect improves the explained variance in students' intention to plagiarise which further justifies the analysis associated with the moderating effect.

Model 1 (Table 2) shows the effect of favourable attitude toward plagiarism on students' intention to plagiarise, controlling for students' socio-demographic characteristics. According to the results, the favourable attitude increases students' intention to plagiarise $(b=0.07, p<0.01)$, thus supporting the H1. This result is consistent with several prior empirical studies (e.g. Curtis et al., 2018; Chudzicka-Czupała et al., 2016; Alleyne \& Phillips, 2011) indicating that students who express positive attitude toward plagiarism are more prone to plagiarise.

Moreover, a positive effect of low subjective norms on students' intention to plagiarise is found, however the effect is not significant $(b=0.01$, ns), rejecting the $\mathrm{H} 2$. Therefore, the evidence obtained is in contrast with those from previous scholars (Alleyne \& Phillips, 2011; Imran \& Nordin, 2013; Hsiao, 2015; Chudzicka-Czupała et al., 2016; Camara et al., 2017; Curtis et al., 2018). However, Beck \& Ajzen (1991) acknowledged that in some samples and some populations most of the intention will be explained by one or two variables, as it is probable that relative importance of each of the components of the TPB model may be different from one population to another. 
Table 2

OLS estimates of the effect on Intention to plagiarism

\begin{tabular}{|c|c|c|c|c|}
\hline \multirow{3}{*}{$\begin{array}{l}\text { Variables } \\
\text { Intercept }\end{array}$} & \multicolumn{4}{|c|}{ Coefficients and significance } \\
\hline & \multicolumn{2}{|c|}{$\begin{array}{c}\text { Model } 1 \\
\text { Direct Effect }\end{array}$} & \multicolumn{2}{|c|}{$\begin{array}{c}\text { Model } 2 \\
\text { Moderating Effect }\end{array}$} \\
\hline & $8.08^{* * *}$ & $(2.56)$ & $8.38^{* * *}$ & $(2.55)$ \\
\hline ATTITUDES & $0.07^{* * *}$ & $(0.03)$ & $0.07^{* * *}$ & $(0.03)$ \\
\hline SUBJECTIVE NORMS & 0.01 & $(0.01)$ & 0.01 & $(0.01)$ \\
\hline PERCEIVED BEHAVIORAL CONTROL & $0.18^{* * *}$ & $(0.03)$ & $0.19^{* * *}$ & $(0.03)$ \\
\hline MORAL OBLIGATION & $0.61^{* * *}$ & $(0.18)$ & $0.65^{* * *}$ & $(0.18)$ \\
\hline ACADEMIC LITERACY & 0.03 & $(0.02)$ & 0.03 & $(0.02)$ \\
\hline COMPUTER LITERACY & 0.07 & $(0.22)$ & 0.02 & $(0.22)$ \\
\hline TEXT MATCHING SOFTWARE & $0.83^{* *}$ & $(0.40)$ & $0.83^{* *}$ & $(0.40)$ \\
\hline ATTITUDES *TEXT MATCHING SOFTWARE & & & $0.11^{*}$ & $(0.06)$ \\
\hline SUBJECTIVE NORMS *TEXT MATCHING SOFTWARE & & & $-0.04^{*}$ & $(0.03)$ \\
\hline $\begin{array}{l}\text { PERCEIVED BEHAVIORAL CONTROL *TEXT } \\
\text { MATCHING SOFTWARE }\end{array}$ & & & 0.06 & $(0.07)$ \\
\hline MORAL OBLIGATION *TEXT MATCHING SOFTWARE & & & $-0.66^{*}$ & $(0.39)$ \\
\hline ACADEMIC LITERACY *TEXT MATCHING SOFTWARE & & & -0.06 & $(0.05)$ \\
\hline COMPUTER LITERACY *TEXT MATCHING SOFTWARE & & & $-1.04^{* * *}$ & $(0.48)$ \\
\hline GENDER & $-0.88^{* * *}$ & $(0.38)$ & $-0.85^{* * *}$ & $(0.38)$ \\
\hline AGE & $-0.17^{* * *}$ & $(0.07)$ & $-0.19^{* * *}$ & $(0.07)$ \\
\hline 1ST YEAR UNDERGRADUATE & 0.24 & $(0.52)$ & 0.08 & $(0.52)$ \\
\hline 2ND YEAR UNDERGRADUATE & 0.49 & $(0.51)$ & 0.32 & $(0.51)$ \\
\hline 4TH YEAR UNDERGRADUATE & $1.10^{* *}$ & $(0.52)$ & $1.15^{* *}$ & $(0.53)$ \\
\hline MASTER LEVEL & $-1.48^{*}$ & $(0.83)$ & $-1.54^{*}$ & $(0.83)$ \\
\hline PhD LEVEL & $-3.72^{* * *}$ & $(1.68)$ & $-2.79^{*}$ & $(1.72)$ \\
\hline CULMULATIVE GRADE POINT AVARAGE-A & $1.03^{*}$ & $(0.57)$ & $1.12^{*}$ & $(0.57)$ \\
\hline CULMULATIVE GRADE POINT AVARAGE-C & -0.23 & $(0.46)$ & -0.27 & $(0.46)$ \\
\hline CULMULATIVE GRADE POINT AVARAGE-D & 0.65 & $(0.54)$ & 0.62 & $(0.54)$ \\
\hline CULMULATIVE GRADE POINT AVARAGE-E & 0.40 & $(0.91)$ & 0.78 & $(0.91)$ \\
\hline REPEATED A YEAR & -0.17 & $(0.48)$ & -0.25 & $(0.48)$ \\
\hline Observations & & & & \\
\hline R-squared & & & & \\
\hline
\end{tabular}

$\left.\left({ }^{*}\right),\left({ }^{* *}\right),{ }^{* * *}\right)$ indicate parameter significance at the 10,5 and 1 per cent level, respectively.

Standard error reported in the bracket.

Regarding the $\mathrm{H}_{3}$, we found that the students' intention to plagiarise increases with low perceived behavioural control $(b=0.18, p<0.01)$ supporting the $\mathrm{H}_{3}$ a while rejecting the $\mathrm{H}_{3} b$. This result also joins previous empirical literature (e.g. Camara et al. 2017; Chudzicka-Czupała et al., 2016; Alleyne \& Phillips, 2011) that stresses that perceived behavioural control is decisive in determining students' intention to plagiarise. Hence, the findings are in contrast with those obtained by Harding et al. (2007) or Passow et al. (2006) that find no support that low perceived behavioural control predicts students' intention to plagiarise. 
In addition, low moral obligation is positively and significantly related to the students' intention to plagiarise $(b=0.61, p<0.01)$. Thus, Hypothesis 4 receives support. Therefore, consistent with previous scholarly work (Passow et al., 2006; Harding et al., 2007; Alleyne \& Phillips, 2011; Imran \& Nordin, 2013; Chudzicka-Czupała et al., 2016) low moral obligation increases students' tendency to plagiarise.

Contrary, low level of academic literacy is not significantly related to the students' intention to plagiarise ( $b=0.03$, ns). Thus, Hypothesis 5 did not receive support. This is in line with Eret \& Oak's (2014) discussion arguing that even when students have knowledge about the academic writing rules, this does not diminish their tendencies to commit plagiarism as they do not necessarily put this knowledge into practice. Furthermore, the authors conclude that understanding of academic writing rules might not be sufficient to establish a strong academic integrity culture. Accordingly, Estow et al. (2011) stress the importance of the hands-on experience and repeated exposure to the topic of plagiarism that are necessary to decrease students' engagement in plagiarism.

Similar results are obtained for the computer literacy. More precisely, low level of computer literacy is not significantly related to the students' intention to plagiarise ( $b=0.07, \mathrm{~ns}$ ), rejecting the H6a while supporting the H6b. The finding corroborates with those from Uzun \& Kilis (2020) and Trushell et al. (2012) who argue that students today do not need to be tech savvy in order to plagiarise as it can be only simple 'copy and paste' strategy, which requires only the basic computer skills.

Surprisingly, we obtained a positive effect of the students' awareness of software utilisation on their intention to plagiarize. Walker (2010) listed several reasons that could explain our finding: (1) lecturers did not explain well potential of the software in identifying plagiarism; (2) students are not dedicated to their studies, so they did not understand the utility of the software; (3) profile of the students; (4) students prefer to 'gamble' as they think if they caught, the university would not take serious action against them; (5) international students have difficulties associated to language and adapting to a new culture; (6) the easy the Internet access makes it 'hard' for students to resist to plagiarise. Further explanation about this finding could be traced in Batane's work (2010), revealing that even when students knew their papers will be checked through the software, $75 \%$ of the students indicated that they reduced the amount of material plagiarised as they believe that they could still get away with that type of academic dishonesty since it was at a lower scale. The author however stressed that the effectiveness of the text matching software could be contingent by other components of academic integrity. Important to underline, it could be also that the student population at the University of Montenegro only recently get familiarized with the text matching software, thus it might still need some additional time that the benefits of the software utilisation can be perceived.

Some results regarding the control variables may also be noticed. Actually, as expected, gender, age, higher level of education and repeating the academic year are inversely related to students' intention to plagiarise while being 3 rd year undergraduate student and having high GPA (GPA=A) drives positively students' intention to plagiarise. 
Table 1, Model 2, displays the results for the moderating effect. Regarding the $\mathrm{H} 7 \mathrm{a}$, we may observe that the awareness of the use of the text matching software (for checking students' papers) weakens the positive relationship between attitude toward plagiarism and intention to plagiarise in a sense, that this relationship is still positive however we obtained importantly lower level of significance $(b=0.11, p=0.10)$. Therefore, we may support the H7a. The results hence suggest that even when students have favourable attitude towards plagiarism, their intention to engage in such behaviour could be importantly diminished by using the text matching software. Turning to the H7b, we may notice that when students are aware of the use of the text matching software, subjective norms will not drive students' intention to plagiarise $(b=-0.04, p=0.109)$. What more, the interaction between low subjective norms and text matching software becomes negative and slightly significant. Accordingly, we accept the $\mathrm{H}_{7} \mathrm{~b}$. Considering the $\mathrm{H}_{7 \mathrm{c}}$, we may notice that the awareness of the use of text matching software neutralises the positive effect between perceived behavioural control and students' intention to plagiarise in the sense that the effect of perceived behavioural control interacted with the awareness of software utilisation on intention to plagiarise becomes non-significant $\left(b=0.06\right.$, ns). Based on the obtained findings we accept the $\mathrm{H}_{7}$. Furthermore, as it can be noticed, H7d is supported $(b=-0.66, p=0.90)$. More precisely, when students are aware of the use of the text matching software, it weakens the positive and significant link between moral obligations and students' intention to plagiarise in the sense that this relation becomes negative and weakly significant. Thus, even if the students consider that plagiarism is not against their ethical values, they are cognisant that the utilisation of the software increases the chances of them being caught, so they will try to avoid it. The result associated to the Hze induces that the interaction between perceived level of academic literacy and the awareness of the use of text matching software does not influence students' intention to plagiarise, however the sign now turns to be negative $(b=-0.06, n s)$. Therefore, we can support the H7e. Finally, the interaction between computer literacy and awareness of the use of the text matching software becomes negative and significant what implies the acceptance of the $\operatorname{H}_{7} f(b=-1.04, p>0.05)$.

Thus, the introduction of our moderating variable - the awareness of the text matching software utilisation - is crucial in order to understand how the ETPB's components relate to students' intention to plagiarise, as this factor may shape their influence on students' intentions. In other words, our findings concerning the moderating effect induce that the relationship between the ETPB's components and intention to plagiarise is subject to the influence of the text matching software utilisation. Therefore, utilisation of the text matching software can deter the intention to plagiarise.

Overall, these findings partially lend support to the ETPB. Hence, the ETPB is efficient in predicting students' intention to plagiarise. However, as our theoretical model and empirical findings suggest, the awareness of the use of text matching software may weaken the positive effects of the ETPB's components. Therefore, ignoring the moderating effect could have misleading effect on the overall conclusion regarding the academic integrity issue. 


\section{Conclusion}

The extended theory of planned behaviour has become an essential framework for examining students' intention to plagiarise (Cronan et al., 2018; Camara et al., 2017; Salehi \& Ghasemzadeh, 2018; Stowe, 2017; Stone et al., 2010; Meng et al., 2014). However, additional components should be also considered when applying this theory (Imran \& Nordin, 2013; Uzun \& Kilis, 2020; Curtis et al., 2018; Stone et al. 2009; Chudzicka-Czupała et al., 2015). Our study used this extended theory of planned behaviour, including (besides attitudes, subjective norms and behaviour control) the moral obligation (Chudzicka-Czupała et al., 2016; Harding et al., 2007) and the two additional components - academic and computer literacy, aiming to interrogate if and to which extent these items influence students' intention to plagiarise. Moreover, for the first time, up to our knowledge, the ETPB model for studying academic dishonesty was expanded to include a moderating variable - awareness of the use of the text matching software. The role of the moderating variable is to challenge the relation between the ETPB's components and students' intention to plagiarise, namely to verify how the use of the text matching software might influence the impact of attitudes towards plagiarism, subjective norms, perceived behavioral control, moral obligation, academic literacy and computer literacy on students' intention to plagiarise.

We find that three components of our ETPB influence positively students' intentions to plagiarise i.e., favorable attitudes towards plagiarism, low perceived behavioral control and low moral obligation. Contrary, the evidences reveal that subjective norms, academic literacy and computer literacy are not significant determinants of students' intention to plagiarise. These results are mostly consistent with the previous findings, which confirmed that components of the ETPB model act as an efficient predictor of students' intention to plagiarise. The only major dissonance is related to the subjective norms, which in our study did not have a significant impact on students' intention to plagiarise. However, in their seminal work Beck \& Ajzen (1991) warned that the relative importance of the subjective norms (as well as other components) is expected to vary in different populations or in relation to different behaviours. But the most important contribution of our study relates to the moderating extension of the ETPB, which reveals how the effect of the ETPB's components on intentions to plagiarise weakens when the students are aware their papers will be checked through the text matching software. Therefore, we may conclude that the text matching software should be used as a supplementary measure to ensure that student respect academic integrity principals (Batane, 2010).

Noteworthy, our findings show that even though the students were informed about software utilisation, it was not sufficient to discourage their intention to plagiarise completely, which implies that the HEIs should implement other strategies in order to eliminate the problem of plagiarism (Batane, 2010). In this vein, Willen (2004) posits that teachers should pay more attention to the way that they present writing to students by demonstrating them the process that includes invention, drafting, collaboration revising, and editing and not only focusing on the final outcome.

This paper makes three theoretical contributions. Firstly, the study further encompasses the extended theory of planned behavior by including two additional 
components, namely the academic and computer literacy. Secondly, in comparison to the previous analyses, rather than investigating only the direct effects of the ETPB's components on students' intention to plagiarise, this study also focuses on the moderating effects, measured by students' awareness of the use of the text matching software, impacting the relations between ETPB's components and intention to plagiarise. Thirdly, most of the studies of academic dishonesty in general, and especially academic dishonesty in the framework of the ETPB, were conducted in the USA with only few (such as Chudzicka-Czupała et al., 2016; Hendy \& Montargot, 2019) using the samples from European countries or even more samples from the developing countries in Europe. Thus our analysis provides additional insights bringing to the general discussion a European perspective and a specific environment of the developing country.

\section{Policy Implications}

Our study has important implications for the policy-makers and integrity officers at the HEIs. In fact, our results undoubtedly reveal that students' awareness of the existence and use of the text matching software acts as a strong impediment to the intention to plagiarase, weakening the positive effects of the relation between the ETPB's components and intention to plagiarise. The results clearly corroborate that even when students have favourable attitude towards plagiarism, consider the academic environment to be dishonest, find relatively easy to plagiarise and have low moral obligation, the introduction of the text matching software can significantly reduce their intention to plagiarise. Based on these findings, we recomend HEIs in the region to further increase use and visibility of the text matching software in order to discourage students from plagiarising. It is evident that the educational institutions might benefit from investing in plagiarism detection software as a part of their strategy of academic integrity. However, software should be used jointly with other activities aimed at strenghtening the academic culture, such as targeted educational interventions, honour codes and promotion of ethical norms. Teachers and managers in education should therefore create comprehensive strategies including, but not limited to, the use of the text matching software as a tool for preventing plagiarism and academic mis-behaviour.

\section{Limitations}

Several limitations of the study should also be acknowledged in order to suggest avenues for future research. First, the link between the ETPB's components and students' intention to plagiarise through the text matching software is only one way in which the ETPB's components may affect students' intentions. Therefore, it would be useful to introduce other potential moderators found relevant in previous literature (Bennett, 2010; Hoo Quah et al., 2012; Van Zyl \& Thomas, 2015; Finn \& Frone, 2004) such as religious orientation, code of honour, online academic integrity tutorials, the severity of punishment, etc. Second, even though this is the first study applying the ETPB in Montenegro, providing important contribution to the topic of academic integrity in developing countries, it would be interesting to examine whether our 
results regarding the moderating effect apply to different countries. Third, the current work can be also improved by addressing some methodological limitations related to our questionnaire. Actually, when measuring academic and computer literacy we used student's subjective perception of their academic and computer skills. However, it has been proved that students often overestimate their actual skills and capacities (Kruger \& Dunning, 1999), hence their subjective evaluation could produce some bias associated to our findings. Therefore, it would be safer to use the objective indicators. Fourth, research in the field would benefit from considering additional components that could be further integrated in the ETPB and might propose a more comprehensive model when examining students' intention to plagiarise.

\section{Acknowledgements}

This manuscript has been produced in the framework of the national project entitled "Strengthening Academic Integrity - Interdisciplinary Research-based Approach to Ethical Behaviour in Higher Education" which was financed by the Ministry of Science of Montenegro.

\section{References}

Ajzen, I. (1991). The theory of planned behavior. Organizational Behavior and Human Decision Processes, 50, 179-211.

Alleyne P., \& Phillipos K. (2011). Exploring academic dishonestly among university in Barbadis: an extension to the theory of planned behavior. Journal of Academic Ethics, 9, 323-338.

ANGELL, L. R. (2006). The relationship of impulsiveness, personal efficacy, and academic motivation to college cheating. College Student Journal, 40(1), 118-131

ASARE, M. (2015). Using the theory of planned behavior to determine the condom use behavior among college students. American Journal of Health Studies, 30 (1), 43-50.

Ashworth, P., BAnnister, P., \& ThORne, P. (1997). Guilty in whose eyes? University students' perceptions of cheating and plagiarism in academic work and assessment. Studies in Higher Education, 22(2), 187-204.

BARON, R. M., \& KenNy, D. A. (1986). The moderator-mediator variable distinction in social psychological research: Conceptual, strategic, and statistical considerations. Journal of Personality and Social Psychology, 51, 1173-1182.

BARry, E. (2006). Can paraphrasing practice help students define plagiarism? College Student Journal, 40, 377-384.

BAILEY, S. (2011). Academic writing: A handbook for international students (3nd ed.). London: Routledge

Batane, T. (2010). Turning to Turnitin to Fight Plagiarism among University Students. Educational Technology \& Society, 13(2), 1-12.

BENNETT, R. (2005). Factors associated with student plagiarism in post-1992 university. AssessmentE Evaluation in Higher Education, 30 (2), 137-162.

BENETT, R. (2017). Online academic integrity: an examination of MBA students' behavioral intent of engaging in plagiarism. Ph.D. Dissertation, University Phoenix.

Beck, L., \& AJzEn, I. (1991). Predicting dishonest actions using the theory of planned behavior. Journal of Research in Personality, 25 (3), 285-301.

Belter, R., \& DU PrÉ, A. (2009). A Strategy to Reduce Plagiarism in an Undergraduate Course. Teaching of Psychology, 36, 257-261. 
BELlACK, J. P. (2004). Why plagiarism matters. Journal of Nursing Education, 43(12), 527-528.

Bilic-Zulle, L., Azman, J., Frkovic, F., \& Petrovecki, M. (2008). Is there an Effective Approach to Detering Students from Plagiarizing? Science and Engineering Ethics, 14, 139-147.

Boend, P., Justice, M., \& Weeks, S. (2009). Promoting academic integrity in higher education. The Community College Enterprise, 15(1) 45-61.

Bradinova, M. (2006). Exploring students' and university teachers' perceptions of plagiarism. Ph.D. Dissertation, Indiana University of Pennsylvania.

Bradley, H. T. (2010). Student Plagiarism and the Use of a Plagiarism Detection Tool by Community College Faculty. Ph.D. Dissertation, Indiana State University.

BRADLEy, E. G. (2015). Using computer simulations and games to prevent student plagiarism. Journal of Education and Technology Systems, 44(2), 240-252.

Braumoeller, B., \& Gaines, B. (2001). Actions do speak louder than words: Deterring plagiarism with the use of plagiarism-detection software. Political Science E Politics, 34, 835-839.

Brennan, T. (2015). The Effect of Turnitin.com on Non Traditional, Graduate Student Awareness, Behavior and Trust. Ph.D. Dissertation, Trident University, Cypress, USA.

Broeckelman-Post, M. A. (2009) Building a Culture of Academic Integrity: The Role of Communication in Creating and Changing Understandings and Enactments of Academic Integrity. Ph.D. Dissertation, the Scripps College of Communication of Ohio University.

Burke, M. (2004). Deterring plagiarism: a new role for librarians. Library Philosophy and Practice, 6 (2), 1-9.

Calvo, S., Celini, L., Morales, A., \& Martines, J. M. G. (2020). Academic Literacy and Student Diversity: Evaluating a Curriculum-Integrated Inclusive Practice Intervention in the United Kingdom. Sustainability, 12 (3), 1155 .

Camara, S. K., Eng-Ziskin, S., Wimberley, L., Dabbour, K. S., \& Lee, C. M. (2017). Predicting Students' Intention to Plagiarize: an Ethical Theoretical Framework. Journal of Academic Ethics, 15, 43-58.

Campbell, C. R., Swift, C. O., \& Denton, L. (200o). Cheating Goes Hi-Tech: Online Research Paper Mills. Journal of Management Education, 24, 726-40.

Carnero, A. M., Percy M.-T., Konda, K. A., Mezones-Holguin, E., Bernabe-Ortiz, A., Alvarado, F., \& CANelo-Aybar, C. (2017). Plagiarism, Cheating and Research Integrity: Case Studies from a Masters Program in Peru. Science and Engineering Ethics, 23 (4), 1183-97.

CArroll, J. (2009). Plagiarism as a Threat to Learning: An Educational Response. In G, Joughin, (Ed.). Assessment, Learning and Judgement in Higher Education: A Critical Review (pp. 115-131). Berlin: Springer.

Carpenter, D. D., Harding, T. S., Finelli, C. J., \& Passow, H. J. (2004). Does academic dishonesty relate to unethical behavior in professional practice? An exploratory study. Science and Engineering Ethics, 10, 311-324.

Chudzicka-CzupaŁa, A., Grabowski, D., Mello, A. L., Kuntz, J., Zaharia, D. V., Hapon, N., \& Boru, D. (2016). Application of the theory of planned behavior in academic cheating research - cross-cultural comparison. Ethics \& Behavior, 26, 638-659.

Cohen, J., Cohen, P., West, S. G., \& Aiken, L. S. (2003). Applied multiple regression/correlation analysis for the behavioral sciences. Mahwah, NJ: Erlbaum.

Compton, J., \& PFAU, M. (20o8). Inoculating against pro-plagiarism justifications: Rational and affective strategies. Journal of Applied Communication Research, 36(1), 98-119.

Cortes-Vera, J. A. (2018). Mexican strategy to promote greater ethics in academic communications through nation-wide access to Turnitin. Information Development, 34(4), 422-427.

Curtis, G. J., Cowcher, E., Greene, B. R., Rundle, K., Paull, M., \& Davis, M. C. (2018). Self-control, injunctive norms, and descriptive norms predict engagement in plagiarism in a theory of planned behavior model. Journal of Academic Ethics, 16(3), 225-239. 
Curtis, G. J., Gouldthorp, B., Thomas, E. F., O’Brien, G. M., \& Correia, H. M. (2013). Online academic-integrity mastery training may improve students' awareness of, and attitudes toward, plagiarism. Psychology Learning E Teaching, 12(3), 282-289.

DAvis, S. F. (1993). Cheating in college is for a career: Academic dishonesty in the 1990s. Paper presented at the The 39th Annual Meeting of the Southeastern Psychological Association, Atlanta, GA.

DAVIS, M. (2007). The role of Turnitin in the formative process of academic writing: A tool for learning and unlearning? Brookes e-Journal of Learning and Teaching, 2(1) Available at: http://bejlt.brookes.ac . uk/article/the_role_of_turnitin_within_the_formative_process_of_academic_writing/

Davis, S., Becker, A., Grover, C. A., \& McGregor, L. (1992). Academic Dishonesty: Prevalence, Determinants, Techniques, and Punishments. Teaching of Psychology, 19 (1), 16-20.

Davis, S. F., \& Ludvigson, H. W. (1995). Additional data on academic dishonesty and a proposal for remediation. Teaching of Psychology, 22, 119-122.

DEN OUdEN, H., \& VAN WIJK, C. (2011). Plagiarism: Punish or prevent? Some experiences with academic copycatting in the Netherlands. Business Communication Quarterly, 74(2), 196-200.

DEVLIN, M., \& GraY, K. (2007). In their own words: a qualitative study of the reasons Australian university students plagiarize. Higher Education Research E Development, 26 (2), 181-198.

Diekhoff, G. M., LaBeff, E. E., Shinohara, K., \& Yasukawa, H. (1999). College cheating in Japan and the United States. Research in Higher Education, 40, 343-353.

EISENBERG, J. (2004). To cheat or not to cheat: effects of moral perspective and situational variables on students' attitudes. Journal of Moral Education, 33(2), 163-178.

ElLERY, K. (2008). An investigation into electronic-source plagiarism in a first-year essay assignment. Assessment and Evaluation in Higher Education, 33(6), 607-617.

Engler, J. N., LANDAU, J. D., \& Epstein, M. (2008). Keeping up with the Joneses: Students' perceptions of academically dishonest behavior. Teaching of Psychology, 35, 99-102.

Ercegovac, Z., \& Richardson, J. V. (2004). Academic Dishonesty, Plagiarism Included, in the Digital Age: A Literature Review. College \& Research Libraries, 65 (4), 301-318.

ERET, E., \& OK, A. (2014). Internet plagiarism in higher education: tendencies, triggering factors and reasons among teacher candidates. Assessment E Evaluation in Higher Education, 39(8), 1002-1016.

Ferguson, L. M. (2013). Student Self-Reported Academically Dishonest Behavior in Two-Year Colleges in the State of Ohio. Ph.D. Dissertation, University of Toledo, USA.

Fishbein, M., \& AJZEN, I. (1975). Belief, attitude, intention, and behaviour: An Introduction to theory and research. Reading, MA: Addison-Wesley.

GenereuX, R. L., \& MCLeOD, B. A. (1995). Circumstances surrounding cheating: A questionnaire study of college students. Research in Higher Education, 36(6), 687-704.

Grebing, R. E. (2015). The effect of online academic tutorial on student perception of cheating. Ph.D. Dissertation, University of Missouri-Columbia, USA.

Groark, M., Oblinger, D. G., \& ChOA, M. (2001). Term paper mills, anti-plagiarism tools, and academic integrity. Educause Review, September/October, 40-48.

Harding, T. S., Mayhew, M. J., Finelli, C. J., \& Carpenter, D. D. (2007). The Theory of Planned Behavior as a Model of Academic Dishonesty in Engineering and Humanities Undergraduates. Ethics and Behavior, 17(3), 255-279.

Hodges, A., Bicкham, T., Schmidt, E., \& Seawright, L. (2017). Challenging the profiles of a plagiarist: a study of abstracts submitted to an international interdisciplinary conference. International Journal for Educational Integrity, 13(7), 1-15.

Hoo Quah, C., WaI, J., Lee, C., \& Stewart, N. (2012). Attitudes of Business Students' Toward Plagiarism. Journal of Academic Ethics, 10 (3), 185-199.

Howard, R. M., \& Davies, L. J. (2009). Plagiarism in the Internet age. Educational Leadership, 66(6), 64-67 
Hendy, N., \& Montargo, M. (2019). Understanding Academic dishonesty among business school students in France using the theory of planned behavior. The International Journal of Management Education, 17, 85-93.

HsiaO, CH. (2015). Impact of ethical and affective variables on cheating: Comparison of undergraduate students with and without jobs. Higher Education, 69, 55-77.

Husain, F., Ghayth K. Al Shaibani, S., \& Madfoodh, O. (2017). Perceptions of and Attitudes toward Plagiarism and Factors Contributing to Plagiarism: A Review of Studies. Journal of Academic Ethics, 15 (2), 167-195.

Imran, A. M., \& Nordin, M. S. (2013). Predicting the Underlying Factors of Academic Dishonesty among Undergraduates in Public Universities: A Path Analysis Approach. Journal of Academic Ethics, 11(2), 103-120.

Jones, D. L. R. (2011) Academic dishonesty: Are more students cheating? Business Communication Quarterly, 74(2), 141-150

LATHrop, A., \& K. Foss. (200o). Student cheating and plagiarism in the Internet era: A wake-up call. Englewood, CA: Libraries Unlimited.

LEASK, B. (2006). Plagiarism, cultural diversity and metaphor - implications for academic staff development. Assessment E Evaluation in Higher Education, 32 (2), 183-199.

LEDWITH, A., \& RísQUEz, A. (2008). Using anti-plagiarism software to promote academic honesty in the context of peer reviewed assignments. Studies in Higher Education, 33(4), 371-384.

Macdonald, R., \& CARroll, J. (2006). Plagiarism - a complex issue requiring a holistic institutional approach. Assessment E Evaluation in Higher Education, 31, 233-245.

Macfarlane, B., Zhang, J., \& Pun, A. (2014). Academic Integrity: A Review of the Literature. Studies in Higher Education, 39(2), 339-358.

Martin, D. (2005). Plagiarism and technology: A tool for coping with plagiarism. Journal of Education for Business, 80, 149-152.

MCCAвE, D. L. (2005). It takes a village: Academic dishonesty \& educational opportunity. Liberal Education, Summer/Fall, 26-31.

McCabe, D. L., \& Treviño, L. K. (1993). Academic Dishonesty: Honor Codes and Other Contextual Influences. The Journal of Higher Education, 64 (5), 522-538

McCabe, D. L., \& Treviño L. K. (1997). Individual and Contextual Influences on Academic Dishonesty: A Multicampus Investigation. Research in Higher Education, 38 (3), 379-396.

McCabe, D. L., Treviño, L. K., \& ButTerfield, K. D. (2002). Honor codes and other contextual influences on academic integrity: A replication and extension of modified honor code settings. Research in Higher Education, 43, 357-378.

McCabe, D. L., \& Treviño, L. K. (1996). What We Know About Cheating in College. Change, 28, 28-33.

McCabe, D. L., Treviño, L., K., \& ButTerfield, K. D. (2001). Cheating in academic institutions: A decade of research. Ethics \& Behavior, 11 (3), 219-233.

Melgoza, P., \& SMith, J. (20o8). Revitalizing an Existing Honor Code Program. Innovative Higher Education, 32(4), 209-210.

Newstead, S., Franklyn-Stokes, A., \& Armstead, P. (1996). Individual Differences in Student Cheating. Journal of Educational Psychology, 88, 229-241.

Nonis, S., \& SwIFT, C. O. (2001). An examination of the relationship between academic dishonesty and workplace dishonesty: A multicampus investigation. Journal of Education for Business, November/December, 6o-76.

Park, H., \& Blenkinsopp, J. (2009). Whistleblowing as Planned Behavior - A survey of South Korean Police Officers. Journal of Business Ethics, 85, 545-556. 
PARK, C. (2003). In other (people's) words: Plagiarism by university students - literature and lessons. Assessment \& Evaluation in Higher Education, 28, 471-488.

Passow, H. J., Mayhew, M. J., Fineldi, C. J., Harding, T. S., \& Carpenter, D. D. (2006). Factors influencing engineering students' decisions to cheat by type of assessment. Research in Higher Education, 47, $643-684$.

PeCORARI, D. (2008). Academic writing and plagiarism: a linguistic analysis. London, New York: Continuum.

Perkins, H. W. (2003). The social norms approach to preventing school and college age substance abuse: $A$ handbook for educators, counselors, and clinicians. San Francisco, CA: Jossey-Bass.

Ramazan, M., Asif, M., \& Siddique, N. (2012). Awareness about plagiarism amongst university students in Pakistan. Higher Education, 64, 73-84.

REID, J. (2005). Academic literacy. Available http://www.une.edu.au/tlc/alobeforeı.htm.

Rogerson, A. M., \& MCCARThy, G. (2017). Using internet based paraphrasing tools: Original work, patch writing or facilitated plagiarism? International Journal for Educational Integrity, 13(2), 1-15.

RoIG, M., \& CASO, M. (2005). Lying and Cheating: Fraudulent Excuse Making, Cheating, and Plagiarism. The Journal of Psychology Interdisciplinary and Applied, 139 (6), 485-494.

Salehi L., \& GHasemzadeh, M. (2018). Application of Theory of Planned Behavior in Prediction of Factors Affecting the Intention of Plagiarism. Journal of Medical Education Development, 11 (31), 52-62.

SELWYN, N. (2008). Not necessarily a bad thing...: A study of online plagiarism amongst undergraduate students. Assessment \& Evaluation in Higher Education, 35 (5), 465-479.

Scouller, K., BonANNo, H., \& SMITH, L. (2008). Student experience and tertiary expectations: factors predicting academic literacy amongst first-year pharmacy students. Studies in Higher Education, 33(2), 167-178.

Selemani, A., Chawinga W. D., Dube, G. (2018). Why do postgraduate students commit plagiarism? An empirical study. International Journal for Educational Integrity, 14, 1-15.

SEMERci, Ç. (2006). The effect of problem-based learning on the critical thinking of students in the Intellectual and Ethical Development Unit. Social Behavior and Personality, 34, 41-50.

Simon, C. A., Carr, J. R., McCullough, S. M., Morgan, S. J., Oleson, T., \& Ressel, M. G. (2004). Student perceptions, institutional commitments and academic dishonesty: who reports in academic dishonesty cases? Assessment and Evaluation in Higher Education, 29, 75-90.

Smyth, M. L., \& DAVIS, J. R. (2004). Perceptions of dishonesty among two-year college students: academic versus business situations. Journal of Business Ethics, 51, 63-73.

Stone, T. H., Kisamore, J. L., \& Jawahar, I. M. (2007). Predicting Academic Dishonesty. Paper presented at the 2007 Management Education Division of the Administrative Sciences Association of Canada, Ottawa, Ontario.

Stone, T. H., JAWAhAR, I. M., \& KisAmore, J. L. (2009). Using the theory of planned behavior and cheating justifications to predict academic misconduct. Career Development International, 14, 221-241.

Stout, D. (2013). Teaching students about plagiarism: What it looks like and how it is measured. Ph.D. Dissertation, Western Michigan University.

Stowe, S. (2017). Will They Or Not? Online Faculty Intentions To Report Student Plagiarism. Academy of Educational Leadership Journal, 21(1).

Sutherland-Smith, W., \& CARR, R. (2005). Turnitin.com: Teacher's perspectives of antiplagiarism software in raising issues of educational integrity. Journal of University Teaching and Learning Practice, 2(3b), 94-101.

SzABo, A., \& Underwood, J. (2004). Cyber cheats: Is information and communication technology fueling academic dishonesty? Active Learning in Higher Education, 5(2), 180-200.

Tindall, I., \& Curtis, G. (2020). Negative Emotionality Predicts Attitudes Toward Plagiarism. Journal of Academic Ethics, 18(1), 89-102. 
Townley, C., \& Parsell, M. (2004). Technology and academic virtue: Student plagiarism through the looking glass. Ethics and Information Technology, 6(4), 271-277.

Trushell, J., Byrne, K., \& Simpson, R. (2012). Cheating behaviours, the Internet and Education undergraduate students. Journal of Computer Assisted Learning, 28(2), 136-145.

UzunA, A. M., \& KILIS, S. (2020). Investigating antecedents of plagiarism using extended theory of planned behavior. Computers \& Education, 144, 103700.

Van Zyl, A., \& Thomas, A. (2015). Academic honesty: Perceptions of millennial university students and the role of moderating variables. Koers, $80(1), 1-15$.

Verschoor, C. (2003). 10 Steps to an effective ethics and compliance program. Strategic Finance, 85(6), 2-4.

WALKER, J. (2010). Measuring plagiarism: Researching what students do, not what they say they do. Studies in Higher Education, 35(1), 41-59.

WANG, Y. (2008). University student online plagiarism. International Journal on E-Learning, 7(4), 743-757.

Weinstein, J. W., \& Dobkin, C. E. (2002). Plagiarism in U.S. Higher Education: Estimating Internet Plagiarism Rates and Testing a Means of Deterrence, Available: http://webdisk.berkeley.edu/ Weinstein/Weinstein-JobMarketPaper.PDF.

WhitLEy, B. E., JR. (1998). Factors associated with cheating among college students: A review. Research in Higher Education, 39, 235-274.

Wilcox, B. L. (2005). Plagiarism in the information age. English Leadership Quarterly, 28(1), 1-2.

Willen, M. (2004). Reflections on the Cultural Climate of Plagiarism. Liberal Education, 9o(4), 55-58.

Yeung, A. H. W., Chu, C. B. L., Chu, S. K., \& Fung, C. K. W. (2018). Exploring junior secondary students' plagiarism behavior. Journal of Librarianship and Information Science, 50(4), 361-373.

\section{Authors}

Sanja Pekovic, University of Montenegro, Cetinjska 4, 810oo, Podgorica, Montenegro, e-mail: psanja@ucg.ac.me

Jovana Vukcevic, University of Montenegro, e-mail: jovanv@ucg.ac.me

Dijana Vuckovic, University of Montenegro, e-mail: dijanav@ucg.ac.me

Rajka Djkovic, University of Montenegro, e-mail: rajkadj@ucg.ac.me

Marijana Blecic, University of Montenegro, e-mail: marijanab@ucg.ac.me 